\title{
SuDS for managing surface water in Diepsloot informal settlement, Johannesburg, South Africa
}

\author{
Anne Fitchett ${ }^{1 *}$ \\ School of Civil and Environmental Engineering, University of the Witwatersrand, Private Bag X3, WITS 2050, South Africa
}

\begin{abstract}
Sustainable drainage systems (SuDS) imitate natural water management processes in catchments that have been degraded due to urbanisation. The aim is to reduce the quantity of stormwater runoff and improve water quality. Management of rainwater in the informal settlement of Diepsloot in Johannesburg is compounded by domestic wastewater discharged into the informal lanes. These lanes fall outside the mandate of the City of Johannesburg's stormwater management system; hence residents need to rely on their own initiatives to address surface-water problems. This preliminary study investigated the introduction of SuDS to enhance existing surface-water interventions, as a low-cost flexible approach. Using action research methods, small-scale interventions were designed, constructed and refined by residents and researchers at two sites close to the Jukskei River. While the primary intention of the research was to reduce standing water in the public areas, water quality testing indicates that the SuDS reduced some pollutants. Nitrate and phosphate concentrations were slightly lowered through the introduction of permeable channels and soakaways, while these interventions had a moderate effect on chemical oxygen demand. The involvement of residents at the two sites was markedly different, reflecting divergent priorities and social dynamics. Spontaneous continuation of the SuDS system at one of the sites indicates successful knowledge and skills exchange. This study was of limited duration with only two sets of water quality tests; therefore, longer term monitoring is strongly advised to be able to give more robust assessment of this type of intervention.
\end{abstract}

Keywords: SuDS, action research, water quality, informal settlements, Diepsloot

\section{INTRODUCTION}

In the City of Johannesburg, informal settlements are predominantly found on the periphery of the City on land that was formerly used for agriculture or pasturage (Harber, 2011). The pressure for land creates the characteristic form of highly dense single-storey dwellings with metal sheeting as the main roofing material (Carruthers, 2008; Mafunganyika, 2011).

Vegetation is sparse and the open spaces between the structures are generally of beaten earth. Residents use cast-off carpeting or precast panels as a 'paving' solution to prevent soil erosion, especially at the entrances to dwellings (Carruthers, 2008; Mafunganyika, 2011). In this way, the natural surface-water regime is almost entirely replaced by impervious surfaces with a high runoff co-efficient (Carruthers, 2008).

Pedestrian lanes take the brunt of rainwater runoff, becoming open drains that progressively erode into gullies. These trap litter, frequently preventing water flow, in extreme cases making the lanes almost impassable (Parkinson et al., 2007). The limited space within dwellings tempts children to play around the litter and stagnant water. In areas that have communal toilets and standpipes located in the lanes, there is also runoff from washing clothes (Carruthers, 2008). Inadequate maintenance of the standpipes, gulleys and toilets in these areas adds to the hygiene and sanitation problems, as well as degrading the public domain as an area of social engagement (Richards et al., 2007). The level of cleanliness and hygiene within the individual households tends to be very high, but the impression to an outsider is of urban degradation (Richards et al., 2007; Mafunganyika, 2011).

*To whom all correspondence should be addressed.

e-mail: Anne.fitchett@wits.ac.za

Received 18 June 2016; accepted in revised form 27 March 2017
Diepsloot informal settlement is situated in the northern periphery of Johannesburg (Harber, 2011). The lack of urban drainage infrastructure and limited waste removal further impact water quality, with pollutants frequently washed into the Jukskei River. Diepsloot is characterised by budget constraints because of perceptions of the temporary nature of the settlement by municipal officials, who are not willing to commit capital expenditure to large-scale interventions (Armitage et al. 2009; Harrison et al., 2014).

This study applied a sustainable drainage system (SuDS) approach in an attempt to mitigate some of the problems of standing surface water in two sites within the least formally settled parts of Diepsloot. The efficacy of the implemented SuDS intervention is assessed via a mixed-methods approach, including water quality testing, the recording of aesthetic conditions before and after the intervention, and through discussions with community members. The results of this study show promise for similar interventions in other informal settlements in southern Africa, if not globally.

\section{SuDS and their applications in informal settlements}

Standard engineering approaches to urban drainage are no longer considered to be best practice, since these methods are unable to restore natural flows (Charlesworth et al., 2003; Ellis, 2012). A movement towards sustainable options in urban drainage is underway (Poleto and Tassi, 2012). SuDS, also referred to as sustainable urban drainage systems, as discussed by Fletcher et al. (2015), are best defined as approaches aimed at imitating natural water management processes which have been wholly or partially eliminated due to the influence of urbanisation (Graham et al., 2012). The use of SuDS can be defined by three coexisting objectives: reduce the quantity, and increase the quality of stormwater to combat the effects of 
urban development, while providing conditions for a healthy and stable ecosystem (Charlesworth et al., 2003; Woods-Ballard et al., 2007). Numerous authors (Fletcher et al., 2015; Lawson et al., 2015; Mguni et al., 2016) include 'amenity' as one of the objectives of SuDS, especially where vegetation is introduced or where elements have multiple uses such as for recreation.

SuDS have gained popularity in the developmental discourse due to the improved capacity to manage stormwater in urban environments where traditional methods of controlling runoff are inadequate (Kirby, 2005; Graham et al., 2012). SuDS are characterized as a sequence of integrated installations that allow excess water to overflow from one element into the next (WoodsBallard et al., 2007). This contrasts with conventional systems, in which each element is intended to take the entire volume of the water entering the system (Ellis et al., 2002; Charlesworth et al., 2003). The lack of published research on the application of SuDS in informal settlements has been well noted (cf. Parkinson et al., 2007; Armitage et al., 2009, 2013; Jiusto and Kenney, 2016). This may be attributed to the transience of inhabitants involved in interventions and the ever-changing built fabric of the settlements. The small scale of public space, the lack of delivery of municipal services, and the physical fluidity and transience of these environments suggests a possible application of SuDS strategies (Armitage et al., 2013; Adegun, 2013; Jiusto and Kenney, 2016; Malulu, 2016).

The use of a series of SuDS imitates a natural catchment by incrementally reducing stormwater volume and speed while increasing the water quality (Woods-Ballard et al., 2007). The water flow through these installations takes longer than the storm duration, delaying the peak flow, thereby reducing stress on existing conventional infrastructure and on the receiving body of water (Jones and Macdonald, 2007). The time delay can also promote settlement of pollutants and recharging of the groundwater, especially if the base of some of the SuDS elements is permeable (Ellis et al., 2012).

Sustainable drainage systems can loosely be classified into three types: vegetated areas; pervious areas; and water storage (Charlesworth et al., 2003). Vegetated systems are designed to absorb more water per unit of area than the natural terrain by slowing down the flow of water, allowing for reduction in pollutants and groundwater recharge (Woods-Ballard et al., 2007). The vegetation takes up some of this water, and absorbs pollutants in the form of nutrients (Charlesworth et al., 2003; Woods-Ballard et al., 2007; Ellis et al., 2012). While vegetated SuDS offer many advantages, they require regular maintenance to remove litter and fatty-acid build-up from domestic wastewater (Parkinson et al., 2007). Pervious solutions allow water to percolate below the surface, into temporary storage or to recharge the groundwater (Brooker, 2011; Poleto and Tassi, 2012). Pervious paving is suited to areas prone to littering, as in the pedestrian lanes in informal settlements (Fitchett, 2014), and facilitates the sedimentation of pollutants (Ellis et al., 2012) However, the pervious medium requires periodic cleaning to preserve the percolation capacity (Jones and Macdonald, 2007). Water storage systems reduce the flood peak by storing water, with particular application in water-stressed regions, allowing for water recycling (Enninful, 2013). This water may need pretreatment to remove contaminants (Woods-Ballard et al., 2007). Sustainable stormwater projects should be incremental, following adaptive management practices to optimise performance (Jones and Macdonald, 2007; Woods-Ballard et al., 2007; Poleto and Tassi, 2012; Pahl-Wostl et al., 2008).

Municipalities are often reluctant to install extensive formal drainage in informal settlements for a number of reasons, including: perceptions of legitimising the occupation of the land; transience of the layout and physical format of the settlement; and because many settlements are located on land that compromises human safety or contributes to environmental degradation (Parkinson et al., 2007; Jiusto and Kenney 2016; Ziervogel et al., 2016). This reluctance on the part of local government prompts the need for residents to manage surface water through their own initiatives and with their own severely limited resources. SuDS offer significant advantages over some of the attempts by locals to imitate conventional systems, such as piping and concreted channels, in that some SuDS applications can be very low-cost, technically simple in installation and maintenance, and can provide a platform for community building. Conversely, learning from informal settlement action research can expand the body of knowledge on SuDS, especially by developing micro-scale interventions and through the use of recycled materials (Fitchett, 2014).

\section{Study site}

The Diepsloot settlement (Fig. 1) dates to 1991, when the municipality of Johannesburg developed a layout plan to resettle people evicted from informal settlements on the northern periphery (Benit, 2002; Mafunganyika, 2011). This was one of the earliest attempts at creating a middle ground between squatting and formal government housing. Since the original layout of Diepsloot, householders of the more formal dwellings have densified their plots with 'backyard shacks' to generate income (Harber, 2011; Mupotsa, 2015). The less formal parts of the settlement are still in a state of transience, despite its 25-year existence.

The main roads in Diepsloot are paved, using conventional road and stormwater design, but the smaller lanes are unpaved, subject to erosion and flooding during summer thunderstorms, with pools of stagnant water forming in places. Erosion creates significant level changes between the lanes and the dwellings, undermining walls and flooring, while in the lower parts the roadway is now considerably above the floor level of the dwellings, making them vulnerable to flooding. The change in ground level creates an additional challenge to any surface-water intervention, as a system that may be effective on completion may become obsolete or even destructive over time.

The climate of Johannesburg is significant in any discussion of SuDS, in that rainfall is highly seasonal, concentrated in the summer months. Moreover, most of the precipitation is in the form of intense thunderstorms of short duration (Tyson, 1986). This places severe stress on formal and informal stormwater systems and regularly results in flooding, an aspect of particular concern in informal settlements where the dwellings are vulnerable to collapse (Malulu, 2016). The seasonality of the rainfall is a major contributor to the high rate of erosion in Diepsloot.

The inhabitants of Diepsloot have adapted their environment to manage surface water, with little planning guidance (Carruthers, 2008; Mafunganyika, 2011). The removal of vegetation, as well as the large amount of impervious surfaces due to rapid densification, has caused a serious problem of surface water runoff in the Diepsloot settlement (Adegun, 2013). Earth access lanes, gullies from wastewater runoff and haphazard dumping are prevalent throughout the denser areas of Diepsloot, and strain the natural ecosystem of the region. Construction rubble and domestic waste dumping also leach into runoff water, contaminating the pools of stagnant water and the nearby Jukskei River (Carruthers, 2008). 


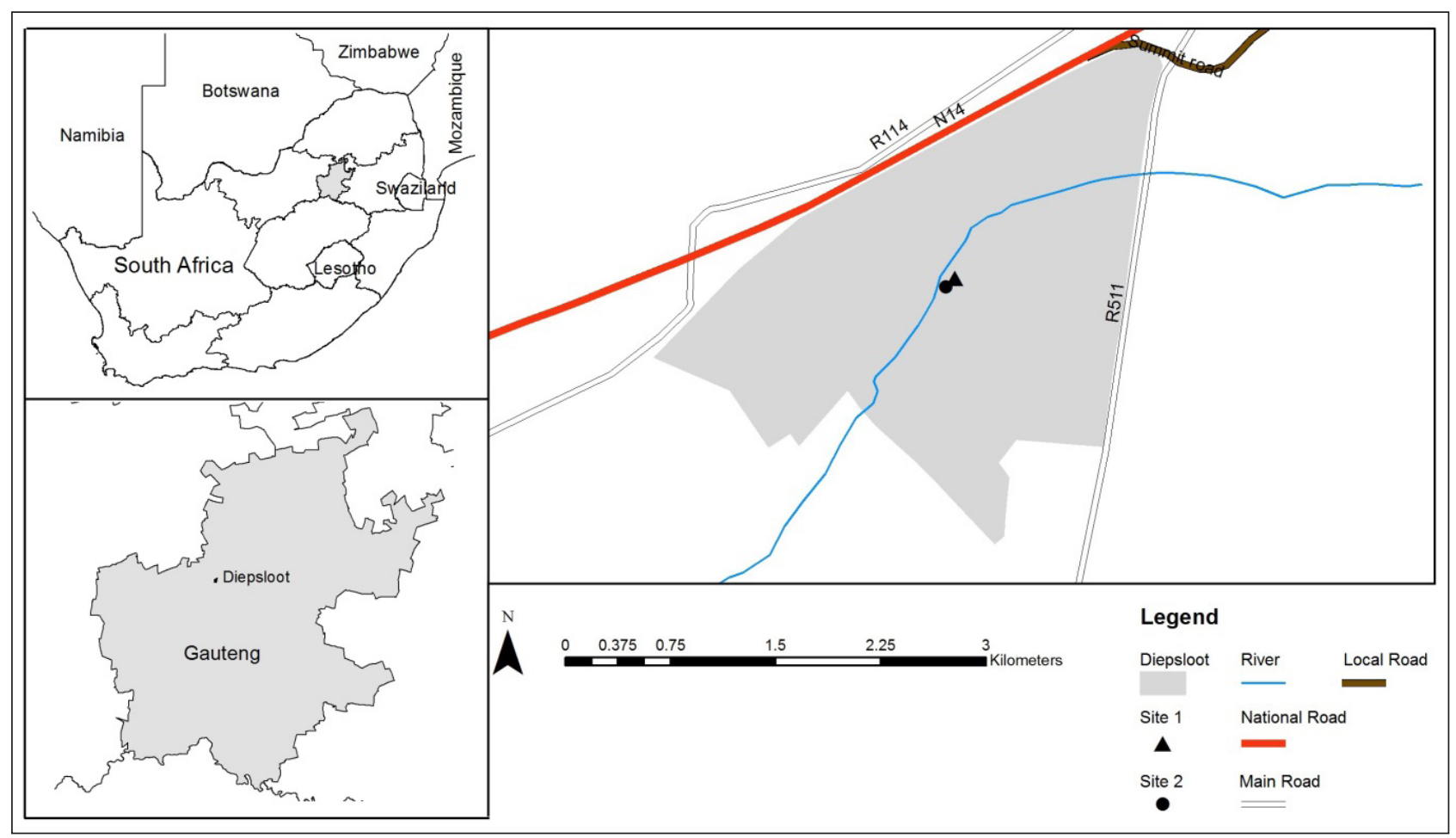

Figure 1

Map of Diepsloot indicating the position of the two study sites

\section{METHODS}

\section{Action research/adaptive co-management}

This research followed the principles of action research (Susman and Evered, 1978) and adaptive co-management, the former in determining the locality for interventions, strategic planning and implementation, while the latter is used for monitoring and tactical readjustment over time (Plummer, et al. 2012). Experience from earlier projects has indicated the importance of intense participatory engagement with residents of the immediate areas of any intervention (Fitchett, 2014). Moreover, literature on SuDS suggests that these should be developed adaptively, with each element of the system being observed and adjusted over time to arrive at an optimal arrangement (PahlWostl et al., 2008). Many of these elements require ongoing maintenance and performance checks, ideally by people living adjacent to them, who can monitor litter accumulation and structural damage that could cause the system to malfunction. A core objective of adaptive co-management is to empower locals to initiate projects with solutions that have been proven, and to adapt them when the environment changes.

\section{Site selection}

The research team, including a resident who is a member of a local community plumbing organization, carried out a broad survey to identify surface water 'hotspots'. A $600 \mathrm{~m}$ stretch of the south bank of the Jukskei River was selected, representing one of the least formal parts of the settlement. The resident team member did a door-to-door survey to assess householders interest in the project. From this, 2 sites were chosen, each with 4 to 8 households. The chosen sites are located within the river floodplain in which years of illegal dumping has created a berm between the flowing water and dwellings (see Fig. 2e). Both sites had rudimentary drainage constructed by residents, which leads through the dump sites before percolating into the river.

\section{Implementation of SuDS}

The design of the interventions at the two sites was driven by a number of factors, namely: site conditions, including solutions already implemented by residents; simplicity of construction and ease of maintenance; and availability of materials, preferably of no re-use value to discourage 'dismantling' (Fitchett, 2014). The process of selection was modelled on the USA Environmental Protection Agency's (USEPA, 1993) Urban Runoff Pollution Prevention and Control Planning handbook, which advises a 2-step process of compiling a comprehensive list of elements, followed by an evaluation and screening process. The first step was carried out by the research team, while the evaluation and selection took place on each site in conjunction with the residents. The second step therefore harnessed local knowledge on the performance of surface water and on suitability in terms of the factors outlined above. Similarity between systems derived from global practice and local solutions often drove the discussion and selection process, with 1 or 2 residents who had carried out interventions taking the lead throughout.

The elements chosen were simplifications of standard SuDS, namely pervious channels, semi-vegetated channels, soakaways and a miniature bio-retention area (cf. Jones and Macdonald, 2007; Woods-Ballard et al., 2007; Brooker, 2011; Poleto and Tassi, 2012). All of the interventions allowed for ease of dismantling and reconfiguration, as a response to the ever-changing physical environment.

The primary objectives of residents were to reduce the prevalence of stagnant water, and minimise the risk of flooding. 


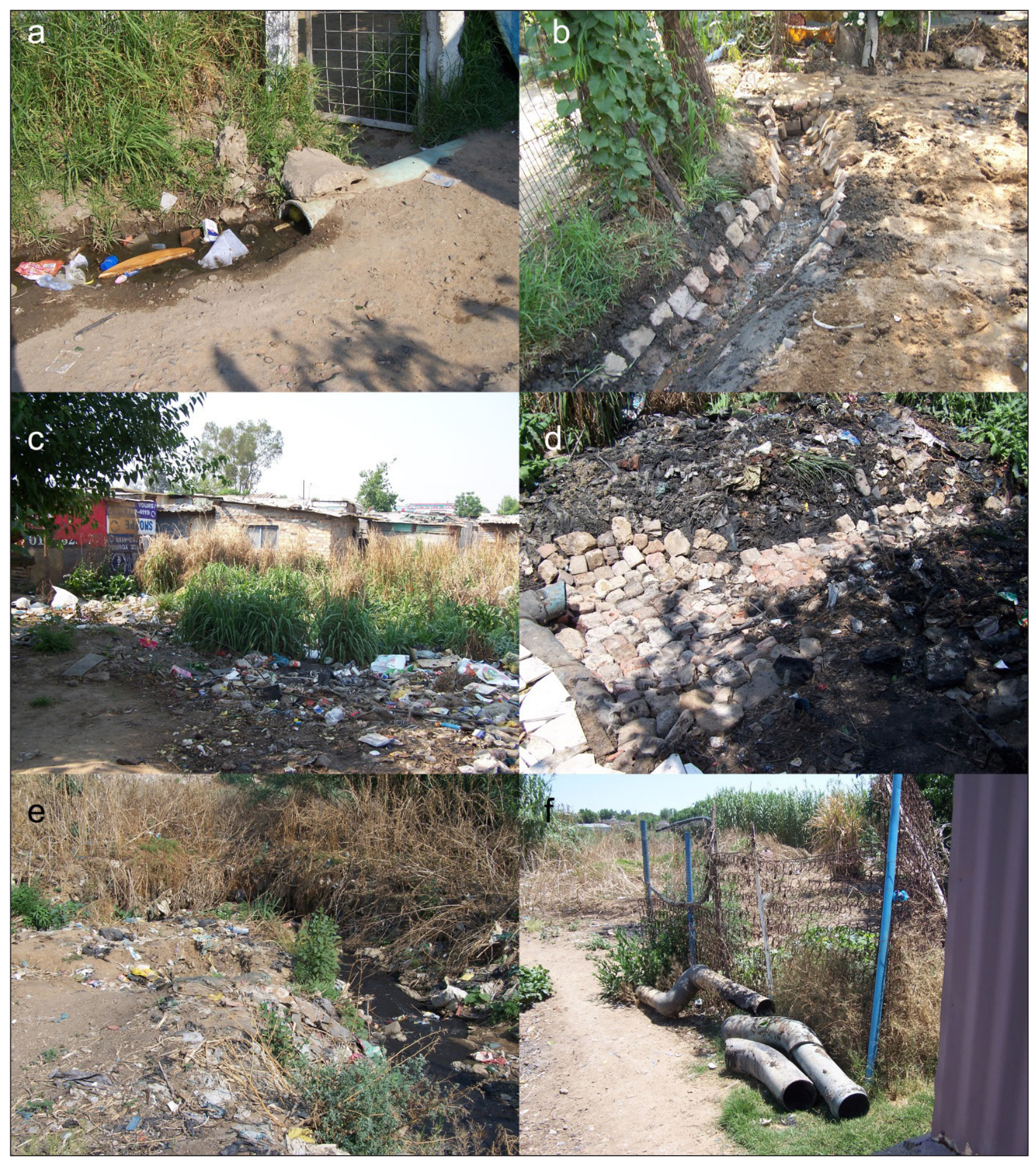

Figure 2

Photo plate Site 1 - a. original pipe inlet near tavern; b. new pervious channel replacing pipe near tavern; c. informal landfill at discharge point of pipework; d. new bio-retention system in original landfill area; e. litter 'berm' adjacent to river; $f$. original pipework removed.

While they appreciated health considerations, their perceptions were that the problems of illegal dumping and informal littering had far greater impact.

\section{Monitoring water infiltration improvement}

Water infiltration was monitored empirically, by residents on a daily basis and by the research team once a week, over 4 months. Each week, the householders at both sites were consulted on the performance of the interventions with regard to domestic water and rain. Ideas for improvements were discussed in an openended format, often leading to modifications, and stimulating the next phase of work. The primary concern of residents was the presence of standing water, leading to odours and providing a tempting place for children to play. The measure of success was deemed to be when all surface water percolates down the drainage channels or into the substrate within a few hours after a rainstorm. 


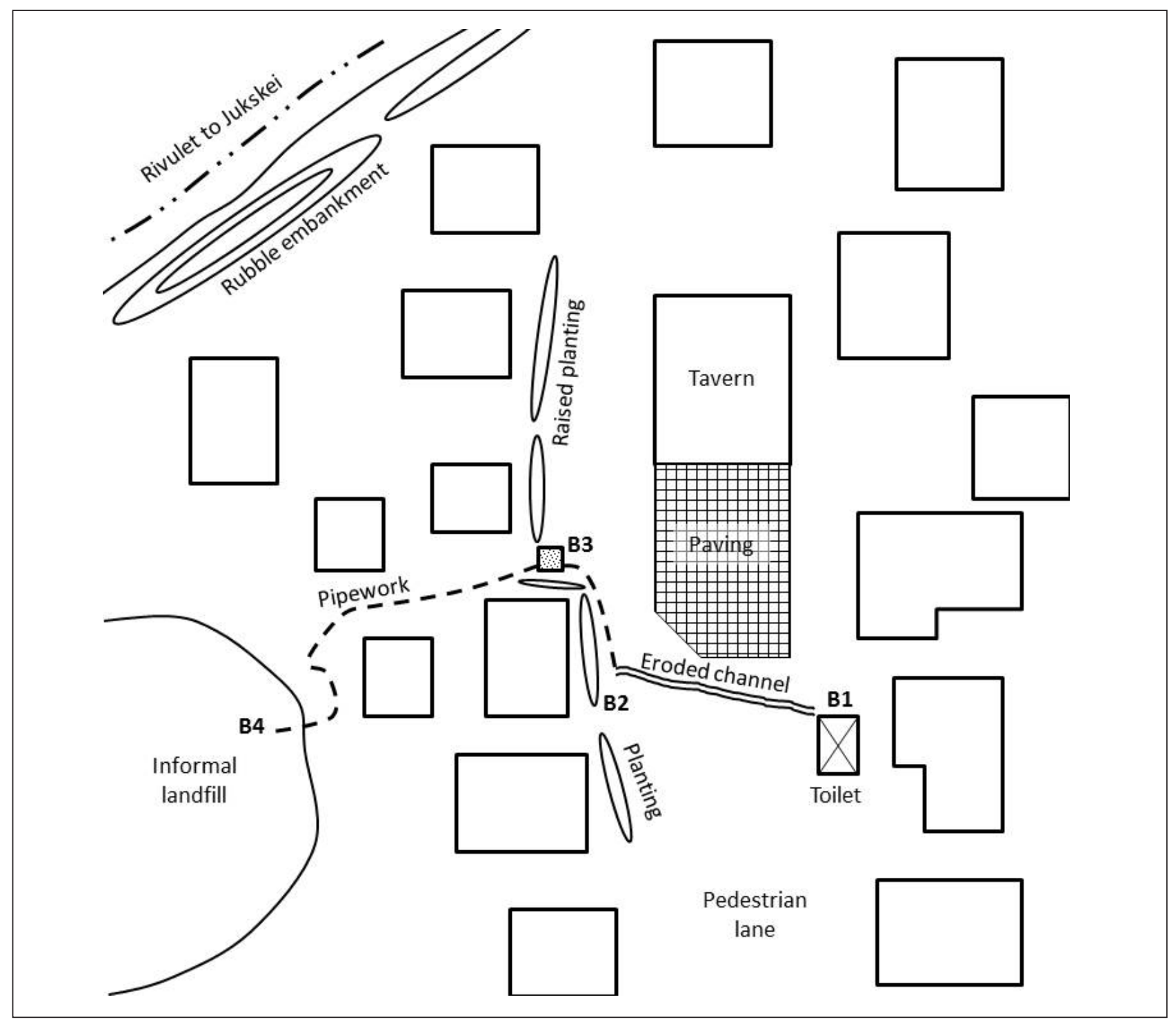

Figure 3

Site 1 before interventions and initial water testing locations

Throughout the implementation process and in subsequent visits, residents at both sites were consulted informally on their perceptions of the effectiveness of the interventions. Six open-ended discussion group sessions were held at each site with 8 to 12 participants aged 18 to 40 years (University of the Witwatersrand Ethics Clearance H16/07/06). These sessions were mediated by the research team member who is a local resident and community plumber in the site area.

\section{Monitoring water quality improvement}

To quantify the influence of the SuDS intervention on runoff management at the two sites, water quality was assessed by comparing water samples before and after the interventions. Samples were manually collected at both sites at the points indicated in Figs 3, 4, 7 and 8 during mid-morning in the middle of the week. The first samples were taken in early summer and the second in late summer, both on overcast days, no less than 3 days after a rainstorm.

Samples were tested in the water quality laboratory at the University of the Witwatersrand. Conductivity and $\mathrm{pH}$ were tested using a Jenway $3020 \mathrm{pH}$ test meter and an electrical conductivity meter. The concentrations of phosphates, nitrates and chemical oxygen demand were tested using Spectroquant test kits.

\section{RESULTS}

At the inception of the project, the visible presence of standing water was the primary clue to the design interventions. At both sites, the water close to the dwellings had algae growing, a moderately noxious smell, and some accumulated litter. Moving towards the river, and as the littering and dumping increased, the stagnant water was black with a very strong odour, suggesting a combination of decomposed soap and landfill leachate.

\section{Site 1}

The residents of this site had introduced several stormwater and surface water management initiatives, including short sections of salvaged PVC piping of different diameters slotted into each other (Fig. 2). The pipe system was approximately $50 \mathrm{~mm}$ below 


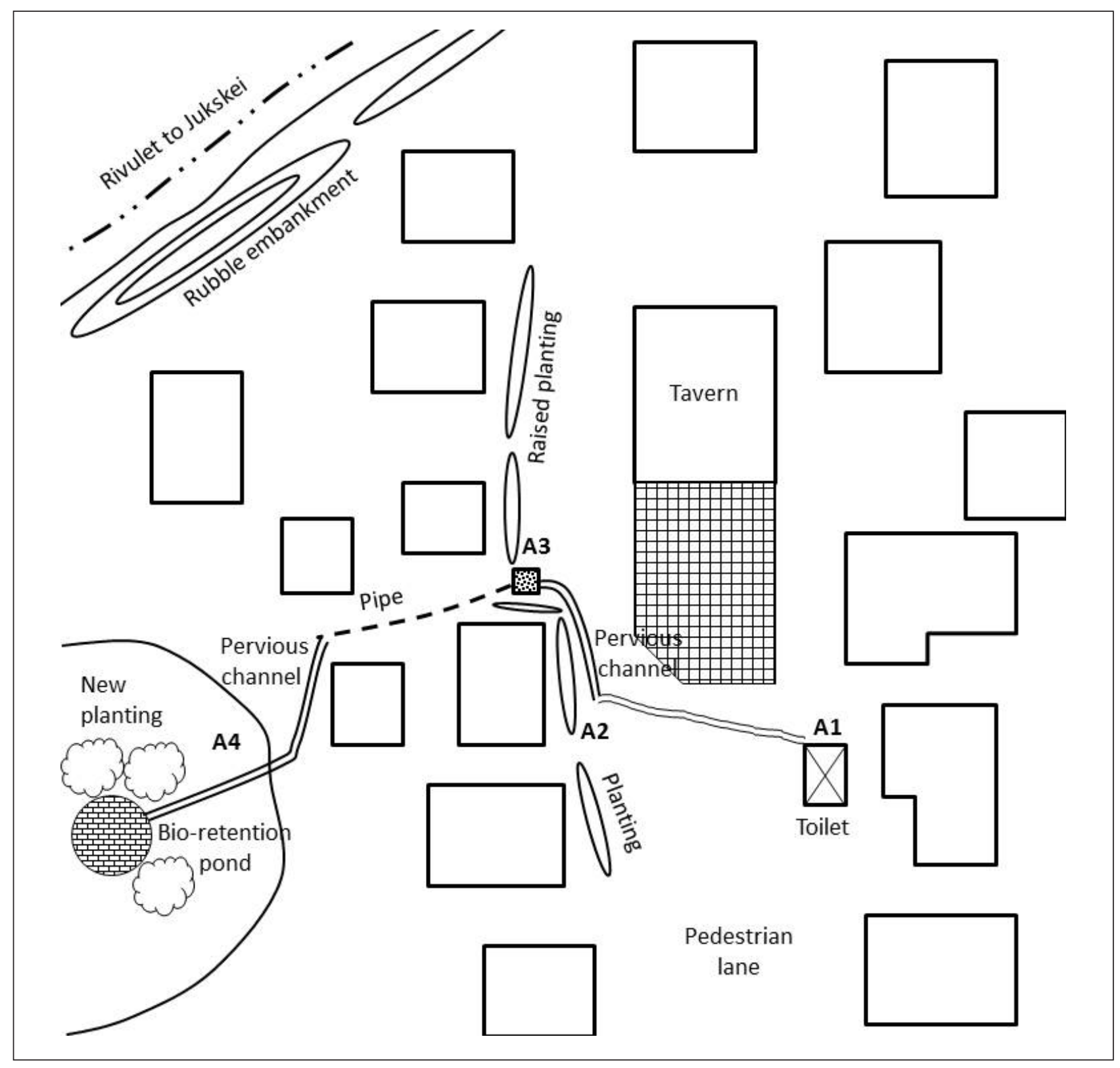

Figure 4

Site 1 with SuDS and final water testing locations

the surface, and had several changes in direction, easily identified by seepage. Water from the communal toilet block traverses the lane via a shallow eroded channel which was collected into the head of the piped system at the fence of one of the dwellings. Along the fences, residents have constructed vegetated strips raised above ground level with rocks and bricks, to deflect water away from their dwellings. A $6 \mathrm{~m}^{2}$ area of paving outside the tavern slopes to the north, and runoff from this area was also collected into the piped system. Before passing closely between two of the dwellings, the pipe discharged into an 'inspection chamber' constructed from a recycled biscuit tin. After passing between the houses, the piping took a number of sharp bends before discharging into a depression in the landfill.

The approach chosen by the residents and research team was to respect the overall layout of the existing interventions, but to replace several of the blocked pipes with open pervious channels, and to adapt the inspection chamber to a soakaway.
In all cases, salvaged broken brick was the preferred material, loosely laid to allow for adaptation during the implementation process, and thereafter to respond to changes in urban form. In the case of the soakaway, this allowed for a dual function as an inspection chamber, as the loose brick can be removed to rod out the retained section of pipe, and the bricks can be cleaned of accumulated sediment at the same time. The use of a soakaway in areas of high concentration of surface water, such as where several channels converge, is promoted by Woods-Ballard et al. (2007) and Armitage et al. (2013).

A bio-retention element was selected as the termination of the SuDS because of the difficulty in linking up to the Jukskei River. Berms of rubble have been constructed alongside the river (Fig. 2e), requiring extensive earthworks to cut through these obstacles. The bio-retention pond was built from broken brick to create a pervious base, and water-tolerant indigenous vegetation was planted on the periphery of the paving (Figs 2 and 4). After 
removal of a section of pipework, a depression was created at the discharge point of the retained pipe and lined with broken brick. A channel lined with brick was extended into the lowest part of the informal landfill area. At the termination of this channel, another depression was shaped and lined with un-grouted halfbricks shaped into a bowl configuration. Vegetation was planted on the periphery to encourage water absorption. The use of a detention pond as a terminating SuDS element before water is permitted to enter a natural aquatic system is promoted by several authors, including Woods-Ballard et al. (2007).

Results of water testing exploring $\mathrm{pH}$, nitrates, phosphates and dissolved oxygen tentatively indicate promising improvements (Fig. 5). The $\mathrm{pH}$ after the interventions increases when compared to the corresponding initial readings, from an average of 7.9 to 8.3 (Fig. 5a). The initial nitrate concentration at Site 1 was higher than the acceptable range (DWAF, 1996a), with a clear increase in the downstream direction (Fig. 5b). Results for the samples following the intervention demonstrate reduced pollution levels: the higher concentration observed for the sample from the entrance to the SuDS system (Fig. 4, A2) is effectively reduced by the permeable paving and soakaway, so much so that the outlet of the system has an acceptable concentration. Acceptable concentrations of phosphates are observed for Site 1, with the exception of the outlet (DWAF, 1996b). This could be due to the severe blockage initially recorded in this pipe, which would have trapped soap long enough for decomposition. The system installed in Site 1 reduced the phosphate concentrations throughout, with a notable $69 \%$ reduction for the outlet, yielding acceptable quality. The chemical oxygen demand (COD) results for samples taken before the SuDS intervention are higher than $75 \mathrm{mg} / \mathrm{L}$ at the outlets, posing environmental risks (DWAF, 1996b). A particularly high reading was obtained for the outlet (Fig. 4, B4). The SuDS intervention yielded improved COD values (Fig. 5d). The interventions at Site 1 have resulted in a clear improvement in the amenity of the public spaces, with no evidence of standing water in any of the areas.

\section{Site 2}

Site 2 has surface water originating in the same street as Site 1 , from a similar communal toilet block. However instead of leading to a mini-wetland, this system leads to a larger drain with a concrete culvert, which was obstructed with rubbish. From the culvert, the water meanders through landfill before discharging into the Jukskei River (Figs 6 and 7).

Residents raised various concerns at Site 2, most importantly that the water running between the dwellings feeds into the large rubbish dump. This causes the drains to block, requiring regular clean-up, of the culvert and the flow-path through the landfill, that cannot be done by hand. The water in the eroded channels was noted initially as being high in volume and turbid with algae growth. The proximity to the landfill raises concerns about the backflow of leachate when there is a sizeable rainstorm.

The eroded gullies were adapted to semi-pervious channels, lining the base with loosely-packed half-bricks and planting on both sides. The channel at B6 in Fig. 7 is predominantly pervious paving with short sections of vegetated sides, whereas the channel at B5 is heavily vegetated with a thin strip of paving down the centre (Charlesworth et al., 2003). The introduction of the pervious paving into the channel allows for partial infiltration of runoff water, as well as reducing erosion and scour. The plants should reduce the velocity of the water, acting as a filter for pollutants and trap for debris (Woods-Ballard et al., 2007); however, this could not be confirmed for this site since flow velocity was not monitored. These channels lead to a soakaway that was installed to encourage further filtration before passing through the culvert (Figs 6 and 8).

The $\mathrm{pH}$ for samples from Site 2 demonstrates an increased alkalinity immediately following the intervention, which

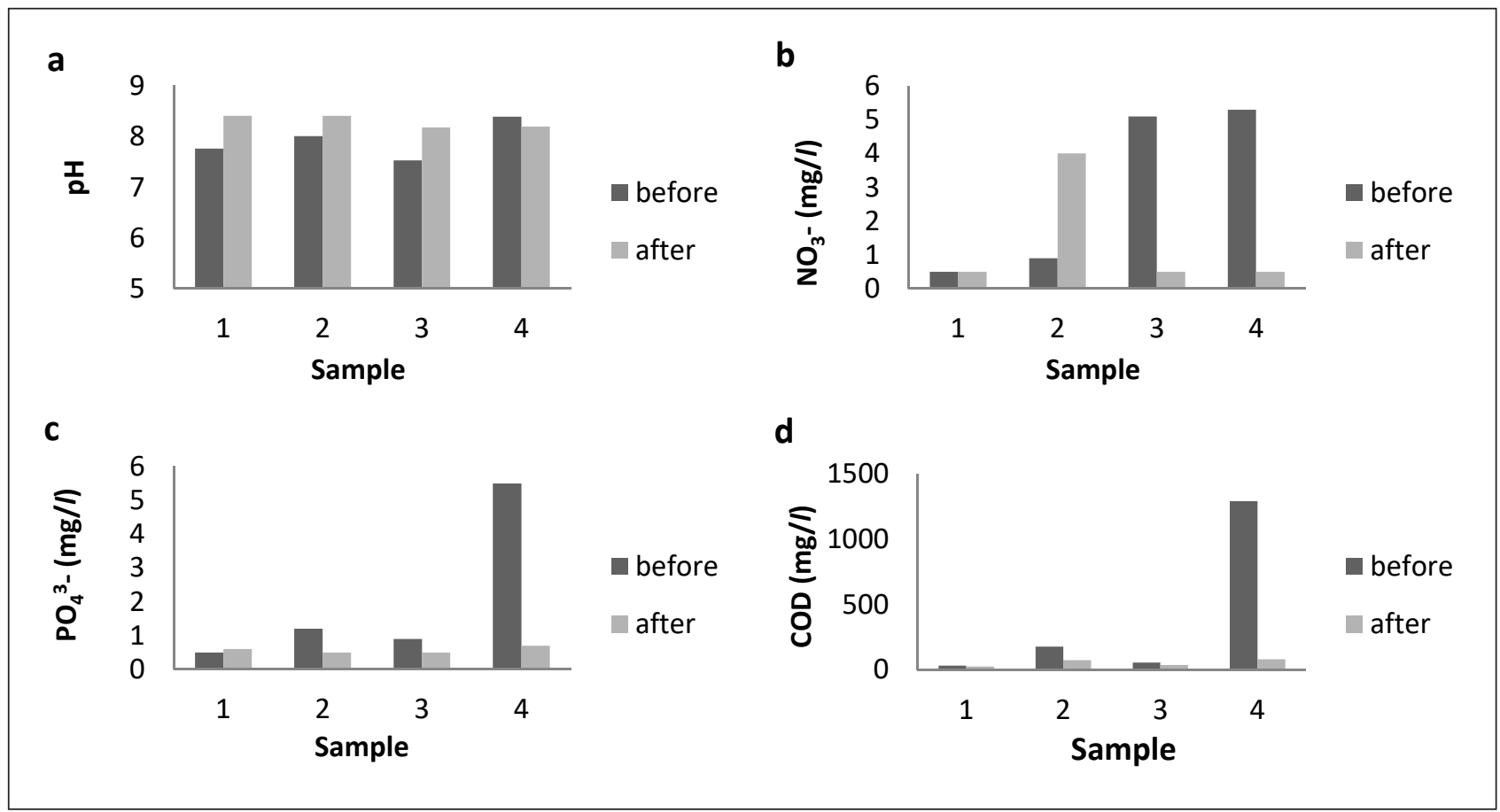

Figure 5

Site 1 water quality results for testing points 1, 2, 3 and 4 as indicated in Figs 3 and 4 . 
could be attributed to an increase in the discharge of domestic wastewater. Site 2 tentatively demonstrates the effectiveness of the SuDS in reducing nitrate concentrations: samples A5 and A6 are above the target concentration, but once the water has travelled along the permeable paving into the soakaway the concentrations reach acceptable levels (DWAF, 1996a, 1996b). The soakaway maintains this concentration (Fig. 8, A8). All samples from Site 2 recorded concentrations within the acceptable range for phosphates. A reduction in phosphate concentration is recorded for samples from water flowing down the permeable paving, and a further reduction is evident when the water passed through the soakaway (Figs 8 and 9c). Before the SuDS intervention, Sample B7 records an increase in chemical oxygen demand from an average of $56.5 \mathrm{mg} / \mathrm{L}$ to $131 \mathrm{mg} / \mathrm{L}$. After the adaptation, the more vegetated channel gave a much higher reading (B6 and A6; 33 and $223 \mathrm{mg} / \mathrm{L}$, respectively), indicative of the introduction of pollutants noted for the $\mathrm{pH}$ at Site 2 . However, after the interventions, the reading at the confluence of the channels $(\mathrm{A} 7 ; 128 \mathrm{mg} / \mathrm{L})$ is slightly lower (B7; $131 \mathrm{mg} / \mathrm{L}$ ), pointing to the effectiveness of the adaptations within the few metres between the sampling locations. The soakaway appears to have a minimally positive effect in reducing the COD, from $72 \mathrm{mg} / \mathrm{L}$ to $67 \mathrm{mg} / \mathrm{L}$ (A7 to A8). After the intervention, standing water in the channels was noticeably reduced in both channels, with the water level lying below the upper level of the brick paving. The water emerging from the culvert pipe was clear on inspection in comparison with the black sludge initially. Residents report that the water visible in parts of the system directly after a rainstorm usually disappears after 2 or 3 days. The interventions appear to be able to cope with the domestic water on days when no rain falls.

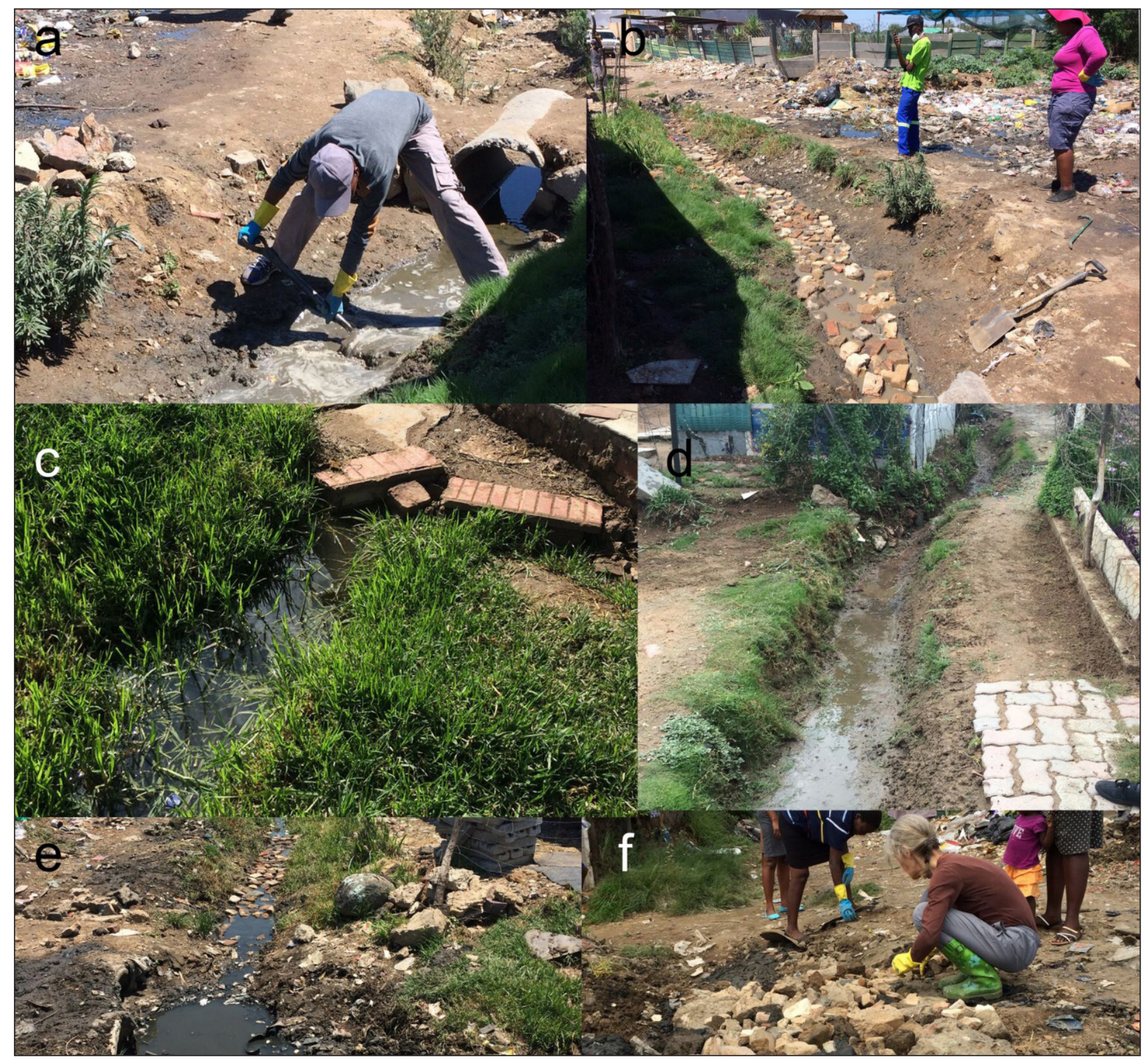

Figure 6

Photo plate Site 2 - a. semi-vegetated drain under construction; $b$. completed semi-vegetated drain; c. vegetated drain before construction; $d$. vegetated drain cleared for introduction of pervious brick base; e. confluence of drains at culvert before construction of soakaway; f. soakaway under construction. 


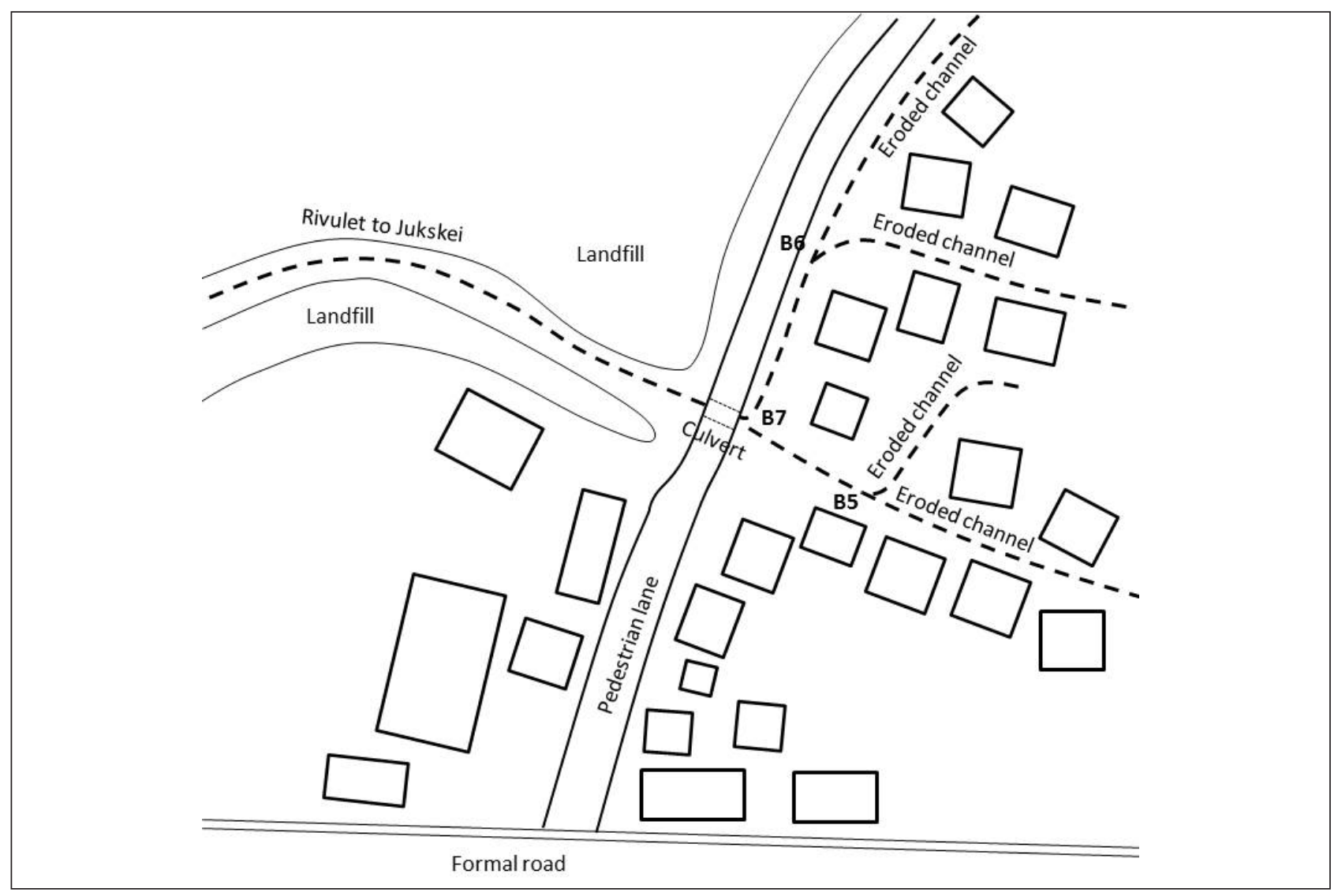

Figure 7

Site 2 before interventions and initial water testing locations

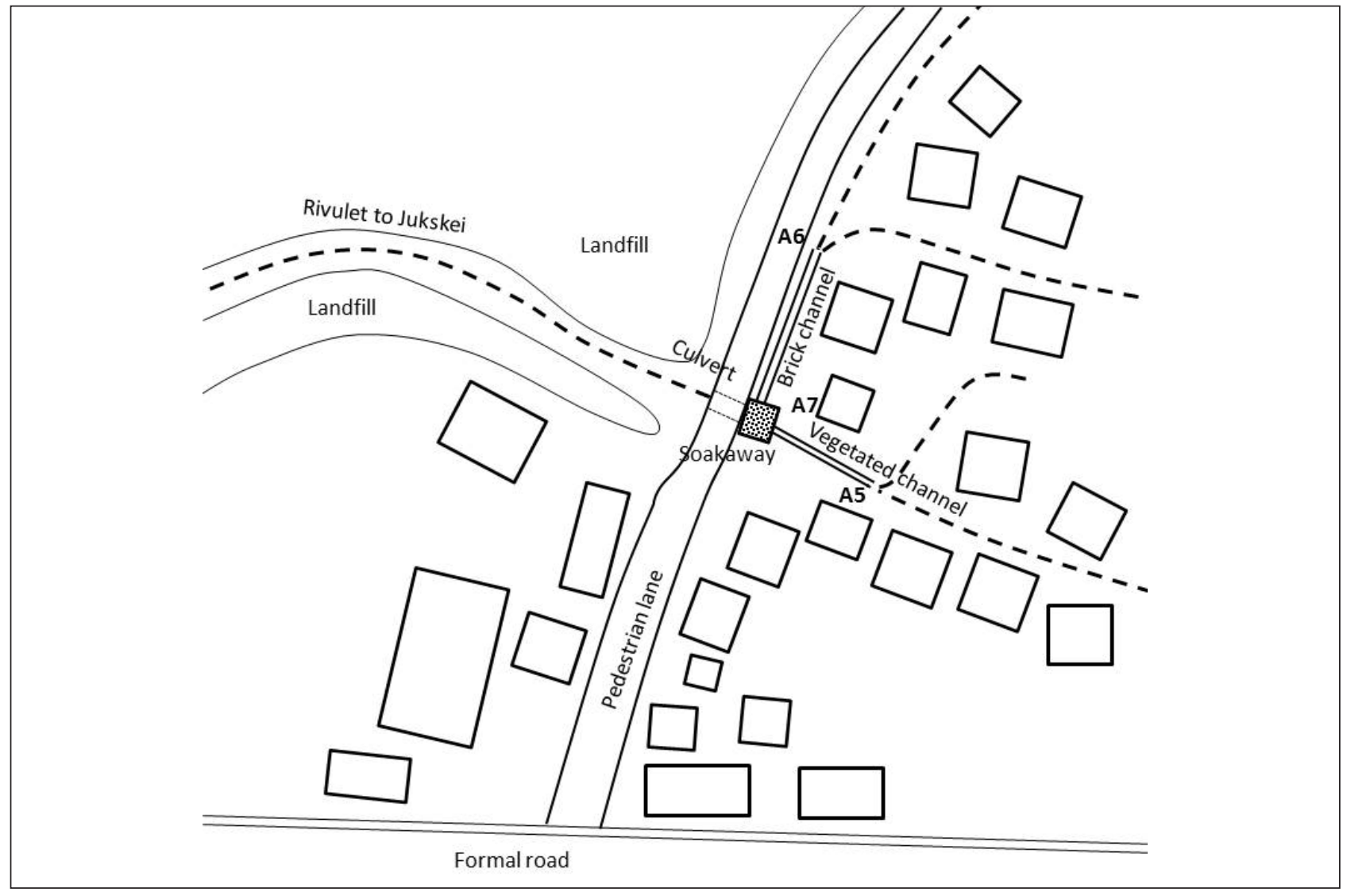

Figure 8

Site 2 with SUDS and final water testing locations 
Follow-up tests could not be carried out at either of the sites because of changes to the physical layout of the buildings and paved areas. This said, the results immediately after the installations of the SuDS suggest reasonable expectation of success in the longer term, especially where residents have a commitment to cleaning and maintaining them.

\section{Community responses and perceptions}

The site selection process ensured that there was a relatively high level of interest in exploring SuDS as a means of enhancing residents' efforts at surface water management. At both of the chosen sites, female residents provided valuable insights and asked penetrating questions in the initial discussion group sessions, but disengaged from the participatory process as the discussion and activities moved into more technical and physical aspects. This was particularly interesting given that the researcher and community facilitator (a community plumber from Diepsloot) were both female. Discussion on possible solutions was structured specifically to promote knowledge symmetry between the researcher and residents (Greenwood and Levin, 2007), with equivalent time spent discussing successful existing interventions, as in approaches derived from the formal body of knowledge on SuDS. Following adaptive co-management principles, solutions were explored that were a fusion of these two knowledge systems (Cundill, 2010; Plummer et al., 2012). Following this first action research instrument of the discussiongroup session, on each of the implementation work-days a section of the planned SuDS system was carried out, with the research team physically working alongside residents. Adaptation and modification were discussed and implemented throughout the physical construction. Each day's work was then evaluated on the subsequent work-day in discussion groups of 4 to 8 residents, which explored adaptations to previous work.
The two sites provided insight into the difficulties in standardising research methods in informal settlements. Despite the proximity of the sites (approximately $200 \mathrm{~m}$ ), the social dynamic was very different. At Site 1, after initial disappointment expressed by participants that they would not be paid for their work (Jiusto and Kenney, 2016), each work-day attracted 6 to 8 residents with a core team of 4 residents. By contrast, Site 2 had a much lower level of social cohesion, involvement on work-days, and commitment to maintenance. A large component of the work at this site required the input of other community groups, including from a nearby middle-income residents' group whose staff cleared an area of landfill on one work-day. This difference in social dynamic could be attributed to the accessibility of each site by non-residents, as described below.

\section{DISCUSSION}

At both sites, the interventions proved to be successful at managing surface water. Reports from residents at Site 1 suggest that, in the absence of rain, the domestic wastewater percolates below the surface almost immediately. After moderate rain, the water permeates below the newly constructed surfaces of the channels within a few hours. At Site 2, water in the more vegetated channel (Fig. 8, A5) retains water longer than in the predominantly paved channel (Fig. 8, A6).

Neither the residents nor the researcher anticipated that the water quality could be substantially improved, given the close proximity of both sites to extensive informal landfill. It was thought that the leachates from the landfill and surface littering would have such a high level of contamination to the surroundings that any intervention of the small scale being implemented would be insignificant. Although there are considerable limitations in deriving results of absolute improvement from two readings, the results were more promising than anticipated. The $\mathrm{pH}$ values are higher (more

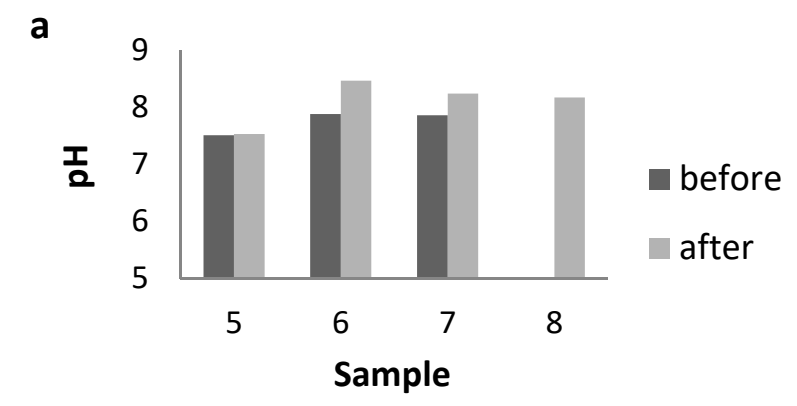

C

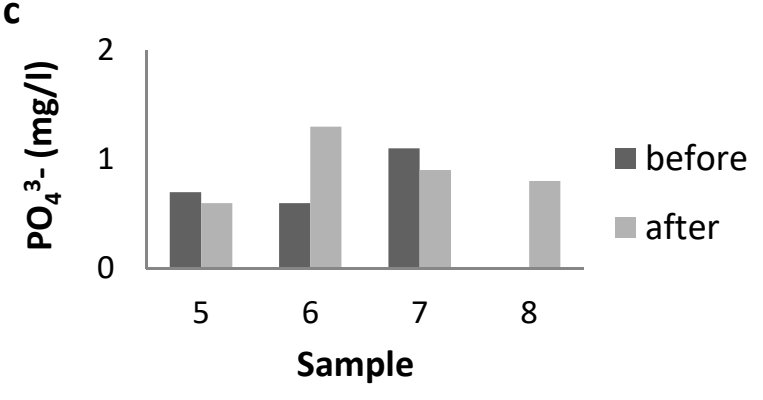

b

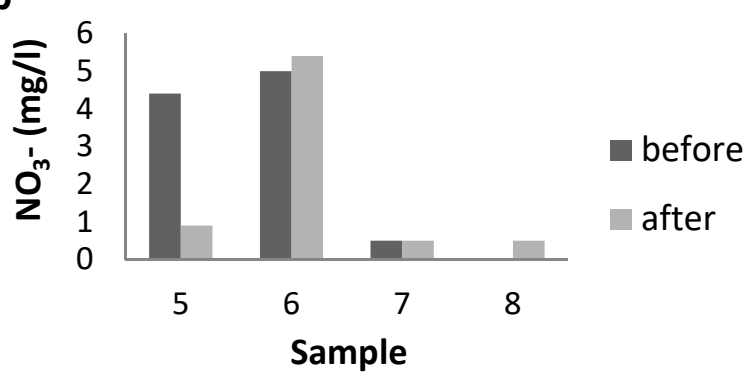

d

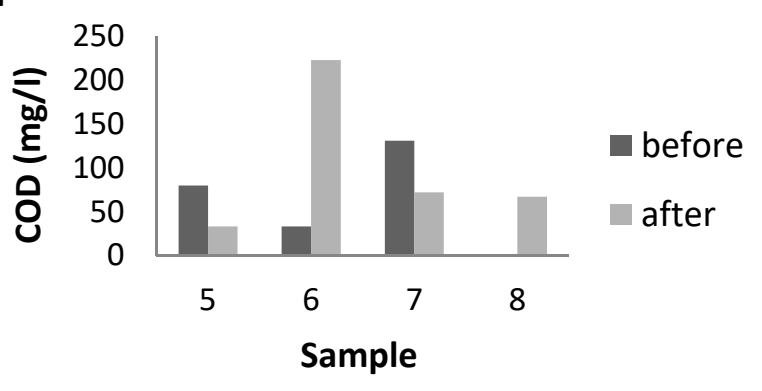

Figure 9

Site 2 water quality results for testing points 1, 2, 3 and 4 as indicated in Figs 7 and 8. 
alkaline) throughout the entire system at both sites after the introduction of the SuDS, suggesting that the $\mathrm{pH}$ of the catchment as a whole is increasing, with the tap reading at Site 1 increasing from 7.76 to 7.81 , and from 7.51 to 7.53 at Site 2 . Consistent with the literature (USEPA, 1993; Charlesworth et al., 2003), the pervious paving ('infiltration' in Table 1) appears to be more effective in reducing levels of nitrates, phosphates and COD than vegetated channels, as analysed above. The soakaways showed improved COD, phosphate and $\mathrm{pH}$ readings. This is consistent with the global literature on the use of SuDS to ameliorate pollution (cf. Ellis et al., 2002, 2012; Charlesworth et al., 2003; Jones and Macdonald, 2007; Parkinson et al., 2007).

\begin{tabular}{|c|c|c|c|}
\hline \multicolumn{4}{|c|}{$\begin{array}{c}\text { TABLE } 1 \\
\text { Expected reduction in pollutants } \\
\end{array}$} \\
\hline & Phosphates & Nitrogen & COD \\
\hline \multicolumn{4}{|l|}{ Dry pond } \\
\hline USEPA, 1993 & Low-med & Low-med & \\
\hline Charlesworth et al., 2003 & Low & Low & Medium \\
\hline Present study & Low & Low & \\
\hline \multicolumn{4}{|l|}{ Infiltration } \\
\hline USEPA, 1993 & Low-med & Med-high & \\
\hline Charlesworth et al., 2003 & High & High & Very high \\
\hline Present study & Low-med & Low-med & Medium \\
\hline \multicolumn{4}{|l|}{ Vegetated } \\
\hline USEPA, 1993 & Low-med & Low-med & \\
\hline Charlesworth et al., 2003 & Low & Low & Low \\
\hline Present study & Low & Low & Low \\
\hline
\end{tabular}

The clear improvement in water quality at both sites strongly speaks to the viability of small-scale interventions; however, this would need to be assessed through ongoing water testing over the longer term, if changing land-use permits. In contrast with conventional piped stormwater systems that merely remove the surface water to another location, the very simple and inexpensive SuDS implemented in this study not only address the removal of the surface water, but also improve the water quality. This is crucial in confirming the applicability of SuDS to the southern African context of informal settlements (Ellis et al., 2002, 2012; Parkinson et al., 2007)

The interrelationship between surface water and litter in an informal settlement is demonstrated to be critical: each has the potential to undermine the other (Harrison et al., 2014). Litter rapidly renders a stormwater intervention dysfunctional, whether SuDS or a conventional approach. Conversely, surface water that is not adequately managed turns relatively inoffensive 'dry litter' into a stagnant morass. Therefore, any intervention that attempts to manage either of these two problems should address the other concurrently, in an integrative project (Armitage et al., 2009).

The findings at Site 1 provide a clear indication of potential for the improvement in water quality through the introduction of SuDS, particularly where pipework installed by residents cannot cope with the volume of littering. Pipe blockages trap domestic wastewater for prolonged periods, allowing the soap to decompose within the pipes, whereas channels are easily monitored and cleaned (Parkinson et al., 2007). Where the use of a pipe is preferable, such as between closely spaced structures, a soakaway at the pipe inlet can reduce litter blockage before entering the closed section. At both sites, improvement to naturally eroded channels by introducing vegetation, and especially pervious paving, appears to improve percolation and visibly reduces standing water, with its associated algal growth and odour. This study shows that pervious paving and soakaways can be installed for almost no cost with materials that would otherwise be contributing to the dumping. Moreover, they can be introduced into very confined spaces without compromising existing use of the public domain.

The outcomes of this research can be considered from three angles: the effects on the social amenity through the reduction of surface water; the improvement in quality of life through improved water quality; and the social learning associated with adaptive co-management processes. Underlying these social dimensions is an ethos of minimising the environmental impact of the interventions, through methods such as using locally recovered waste materials in construction. The enhancement of the public domain was noted by residents at both sites, prompting the spontaneous expansion of SuDS interventions at Site 1 by extending the channel system and planting more vegetation in the bio-retention pond. Routine clearing of litter is being managed by a resident who has emerged as the 'champion' of the SuDS approach in his neighbourhood.

From the purely social perspective, the dynamic at the scale of a cluster of households appears to play a significant part in the success of the installation, adaptation phase and ongoing maintenance that is so critical to the effectiveness of any SuDS system. Site 1, located at the end of a lane, appears to have strong social cohesion, with at least one of the residents standing out as a natural leader and initiator. All of the families within this site were enthusiastic about the project from the initial discussions through to the present, as evident in the ongoing extensions and improvements that the residents are spontaneously carrying out. An important factor could be that the only 'outsiders' regularly frequenting this site are a handful of patrons to the tavern, who seem to be the main generators of the small amount of litter in the lane. On the river side of the site, there is still some evidence of domestic dumping, but this is of fairly small scale. By contrast, Site 2 was socially fragmented. Only two of the residents appeared to have any real interest in the project, indicating that surface water management was low on their list of priorities. This view is supported by the frequent experience of residents dumping buckets of domestic wastewater into the channels and onto the landfill area, even as work was in progress. The predominant view of the residents at Site 2 was that their major concern was the landfill and that surface water was not a priority (Ziervogel and Taylor, 2008). They also shared the view that solid waste removal, surface water management and similar issues should be addressed by the municipality (cf. Carden et al., 2007; Douglas et al., 2008; Armitage et al., 2009).

The location of Site 2 may be significant, both in determining the social dynamic and in shaping attitudes. Its proximity to a formal asphalt road encourages the influx of a large number of non-residents into the area. It is also a short-cut pedestrian route from the formal road into the adjacent areas. It appears that people who are not residents of this particular site regularly use the area for dumping domestic waste, and the lane off the asphalt road is wide enough to allow for small trucks to dump construction waste. This breeds a sense of despondency in the residents, in that any intervention on their part is immediately vulnerable to these external role-players. Despite this, one of the residents has shown some initiative in adopting some of the possible interventions discussed at the beginning of the 
action research process, but only immediately adjacent to his own dwelling.

Another important finding of the research lies in the adoption of local practices with regard to recycling. Every one of the interventions evolved from an exploration of materials available in the immediate area, mostly in the form of dumped construction waste. The material of choice was broken bricks, since they are structurally and environmentally robust, versatile, and easy to use, even by inexperienced workers. This approach requires an inversion of the conventional engineering method, in which a problem is defined and analysed; a solution is designed with pre-determined materials and specifications, followed by implementation to the specification. When this process is inverted, the design evolves from an interaction of a range of possible types of intervention and the materials at hand. In some cases, the intervention can be improved with the inclusion of purchased materials, such as a small piece of geotextile membrane for the soakaway at Site 1, but more often the problem can be solved through the same ingenuity that is prevalent throughout the informal settlement (Fitchett, 2014).

A notable limitation of this study is in the short time-frame in which it has been implemented and monitored, which prevents any conclusions on the sustainability of the interventions, from both the perspective of improved water quality and in meeting the objective of reducing surface water (Armitage 2009). This is common to research undertaken in informal settlements, particularly where open land is rapidly transformed into dwelling spaces. An ongoing programme of follow-up visits would be desirable in order to assess the physical robustness of the interventions, responses from residents and water quality testing. Moreover, given the dynamic nature of informal settlements, modifications to the physical layout of the study area and changes in population size should be tracked to ascertain the long-term effectiveness of the SuDS approach in the study sites.

\section{CONCLUSIONS}

The community is exposed to many health risks from contaminated water sources and pollutants that are discarded into eroded gullies and channels (Carruthers, 2008). One of the benefits of the introduction of SuDS is the improved water quality of the runoff, which reduces the health risks associated with the polluted water. From the findings of the tested water samples before and after the SuDS interventions were made, a reduction in many pollutants can be seen. This is indicative of the effectiveness of the SuDS interventions in improving surface runoff quality. Looking at the larger scale of the informal settlement, it can be argued that green infrastructure could substantially improve the water quality, thereby reducing the risk and spread of water-borne illnesses associated with poor sanitation. An important aspect for future research is to monitor the effectiveness of these smallscale interventions in reducing $E$. coli. The present research was limited by access to laboratory facilities that could test for this contaminant; however, it should be included in future studies into the application of SuDS in informal settlements.

The widespread introduction and integration of such interventions in an informal settlement requires a complex, multi-disciplinary approach because of the social, environmental and economic dimensions (Parkinson et al., 2007). Communities from different areas within the settlement can be expected to have differing priorities (Ziervogel and Taylor, 2008), views on environmental responsibility and attitudes to the interventions. As seen in this project, some community members took on a very committed role in initiating SuDS within their area, especially after the first interventions were completed. Through intensive interaction with communities, residents can be committed to driving the introduction and integration of SuDS as complementary to the existing conventional drainage systems (Harrison et al., 2014). It has been recognised that top-down participatory approaches do not address community needs and little trust is gained (Cundill, 2010). In this study, a firm relationship with the community was established from the outset, which provided a platform for knowledge exchange. Selfinitiated SuDS projects indicate that the participatory approaches used were successful in building confidence in these methods, and that the knowledge exchange was effective.

Technical skills and knowledge acquired by residents can be determined firstly from the discussion group sessions, in which the more active participants made proposals that showed appreciation of the role and effectiveness of interventions carried out on previous work-days. Secondly, the expansion of the SuDS intervention at Site 1, using methods developed during the work-days, indicates that lessons from this interaction have been accepted and internalised by some members of the community. It will be interesting to monitor the extent to which these principles and methods are taken up outside of the two study sites, as evidence of a more widespread knowledge exchange.

\section{ACKNOWLEDGEMENTS}

This research was funded by the Gauteng City-Region

Observatory.

\section{REFERENCES}

ADEGUN OB (2013) Sustainable stormwater management in Johannesburg's informal settlements. MBEH Research Report, University of the Witwatersrand, Johannesburg.

ARMITAGE N, WINTER K, SPIEGEL A and KRUGER E (2009) Community-focused greywater management in two informal settlements in South Africa. Water Sci. Technol. 59 (12) 2341-2350. https://doi.org/10.2166/wst.2009.294

ARMITAGE N, DUNSTAN J, FISHER-JEFFES L, SPIEGEL A, VICE $\mathrm{M}$ and WINTER K (2013) Alternative technology for stormwater management: The South African guidelines for sustainable drainage systems. WRC Report No. TT 558/13. Water Research Commission, Pretoria.

BENIT C (2002) The rise or fall of the 'community'? Post-apartheid housing policy in Diepsloot, Johannesburg. Urban Forum 13 (2) 47-66. https://doi.org/10.1007/s12132-002-0013-2

BROOKER C (2011) Stormwater Management Principles. CBA Specialist Engineers, Johannesburg.

CARDEN K, ARMITAGE N, SICHONE O and WINTER K (2007) The use and disposal of greywater in the non-sewered areas of South Africa: Part 2 - Greywater management options. Water SA 33 (4) 433-441.

CARRUTHERS J (2008) Dainfern and Diepsloot: Environmental justice and environmental history in Johannesburg, South Africa. Environ. Justice 1 (3) 121-125. https://doi.org/10.1089/env.2008.0526

CHARLESWORTH SM, HARKER E and RICKARD S (2003) A review of sustainable drainage systems (SUDS): A soft option for hard drainage questions. Geography 88 (2) 99-107.

CUNDILL G (2010) Monitoring social learning processes in adaptive co-management: three case studies from South Africa. Ecol. Soc. 15 (3) 28-47. https://doi.org/10.5751/ES-03467-150328

DOUGLAS I, ALAM K, MAGHENDA M, MCDONNELL Y, MCLEAN L and CAMPBELL J (2008) Unjust waters: climate change, flooding and the urban poor in Africa. Environ. Urbanization 20 (1) 187-205. https://doi.org/10.1177/0956247808089156

DWAF (Department of Water Affairs and Forestry, South Africa) (1996a) South African Water Quality Guidelines (second edition). Volume 1: Domestic Use. Department of Water Affairs and Forestry, Pretoria. 
DWAF (Department of Water Affairs and Forestry, South Africa) (1996b) South African Water Quality Guidelines. Volume 7: Aquatic Ecosystems. Department of Water Affairs and Forestry, Pretoria

ELLIS JB, D'ARCY BJ and CHATFIELD PR (2002) Sustainable urban-drainage systems and catchment planning. J. Chart. Inst. Water Environ. Manage. 16 286-291. https://doi. org/10.1111/j.1747-6593.2002.tb00418.x

ELLIS JB, REVITT DM and LUNDY L (2012) An impact assessment methodology for urban surface runoff quality following best practise treatment. Sci. Total Environ. 416 172-179. https://doi.org/10.1016/j. scitotenv.2011.12.003

ENNINFUL J (2013) Rainwater harvesting: A sustainable practice for low-income housing in South Africa. MSc Research Report, University of the Witwatersrand.

FITCHETT A (2014) Adaptive co-management in the context of informal settlements. Urban Forum 25 355-374. https://doi. org/10.1007/s12132-013-9215-z

FLETCHER T, SHUSTER W, HUNT WF, ASHLEY R, BUTLER D, ARTHUR S, TROWSDALE S, BARRAUD S, SEMADENI-DAVIES A BERTRAND-KRAJEWSKIH J-L MIKKELSENJ PS, RIVARD G, UHL $M$, DAGENAIS D and VIKLANDER M (2015) SUDS, LID, BMPs, WSUD and more - The evolution and application of terminology surrounding urban drainage. Urban Water J. 12 (7) 525-542. https:// doi.org/10.1080/1573062X.2014.916314

GRAHAM A, DAY J, BRAY B and MACKENZIE S (2012) Sustainable Drainage Systems. Wildfowl and Wetland Trust, London.

GREENWOOD DJ and LEVIN M (2007) Introduction to Action Research. Sage, Thousand Oaks. https://doi.org/10.4135/9781412984614

Harber A (2011) Diepsloot. Jonathan Ball, Johannesburg.

HARRISON P, BOBBINS K, CULWICK C, HUMBY T-L, LA MANTIA C, TODES A and WEAKLEY D (2014) Urban resilience thinking for municipalities. University of the Witwatersrand and Gauteng CityRegion Observatory, Johannesburg.

JIUSTO S and KENNEY M (2016) Hard rain gonna fall: Strategies for sustainable urban drainage in informal settlements. Urban Water J. 13 (3) 253-269. https://doi.org/10.1080/1573062X.2014.991329

JONES P and MACDONALD N (2007) Making space for unruly water: Sustainable drainage systems and the disciplining of surface runoff. Geoforum 28 534-544.

KIRBY A (2005) SUDS-innovation or a tried and tested practice? Proc. ICE-Municipal Eng. 158 115-122. https://doi.org/10.1680/ muen.2005.158.2.115

LAWSON E, THORNE C, WRIGHT N, FENNER R, ARTHUR S, LAMOND J, KILSBY C, MANT J, SMMITH L, AHILAN S, ALLEN D, EVERETT G, GLENIS V, HOANG L and MORGAN M (2015) Evaluating the multiple benefits of a Blue-Green Vision for urban surface water management. In: UDG Autumn Conference and Exhibition 2015, 4-6 November 2015, Chester UK. URL: http:// eprints.whiterose.ac.uk/92857/.
MAFUNGANYIKA G (2011) The importance of environmental laws in housing developments: Lessons from the Diepsloot housing project. S. Afr. Prop. Law 26 203-228.

MALULU I (2016) Opportunities for integrating sustainable urban drainage systems (SuDS) in informal settlements as part of stormwater management. MPhil dissertation, University of Stellenbosch.

MGUNI P, HERSLUND L and BERGEN JENSEN M (2016) Sustainable urban drainage systems: examining the potential for green infrastructure-based stormwater management for Sub-Saharan cities. Nat. Hazards 82 S241-S257. https://doi.org/10.1007/ s11069-016-2309-x

MUPOTSA D (2015) Diepsloot. S. Afr. Hist. J. http://dx.doi.org/10.1080/ 02582473.2015 .1031816

PAHL-WOSTL C, KABAT P and MÖLTGEN J (eds.) (2008) Adaptive and Integrated Water Management: Coping with Complexity. Springer Verlag, Heidelberg.

PARKINSON J, TAYLER K and MARK O (2007) Planning and design of urban drainage systems in informal settlements in developing countries. Urban Water J. 4 137-149. https://doi. org/10.1080/15730620701464224

PLUMMER R, CRONA B, ARMITAGE DR, OLSSON P, TENGO M and YUDINA O (2012) Adaptive comanagement: a systematic review and analysis. Ecol. Soc. 17 (3) 11. https://doi.org/10.5751/ es-04952-170311

POLETO C and TASSI R (2012) Sustainable Urban Drainage Systems. INTECH Open Access Publisher, New York. https://doi. org/10.5772/34491

RICHARDS R, O'LEARY B and MUTSONZIWA K (2007) Measuring quality of life in informal settlements in South Africa. Soc. Indic. Res. 81 375-388. https://doi.org/10.1007/s11205-006-9014-1

SUSMAN GI and EVERED RD (1978) An assessment of the scientific merits of action research. Adm. Sci. Q. 23 (4) 582-603. https://doi. org/10.2307/2392581

TYSON PD (1986) Climatic Change and Variability in Southern Africa. Oxford University Press, Cape Town.

USEPA (United States Environmental Protection Agency) (1993) Urban Runoff Pollution Prevention and Control Planning. United States Environmental Protection Agency, Cincinnati.Woods-Ballard B, Kellagher R, Martin P, Jefferies C, Bray R and Shaffer P (2007) The SUDS Manual. Ciria, London.

ZIERVOGEL G and TAYLOR A (2008) Feeling stressed: Integrating climate adaptation with other priorities in South Africa. Environ. Sci. Polic. Sustainable Dev. 50 (2) 32-41. https://doi.org/10.3200/ ENVT.50.2.32-41

ZIERVOGEL G, WADDELL J, SMIT W and TAYLOR A (2016) Flooding in Cape Town's informal settlements: barriers to collaborative urban risk governance. S. Afr. Geogr. J. 98 (1) 1-20. https://doi.org/10.1080/ 03736245.2014 .924867 